\title{
Randomized Trial of a Health IT Tool to Support Between-Visit-Based Laboratory Monitoring for Chronic Disease Medication Prescriptions
}

\author{
Richard W. Grant, MD MPH' ${ }^{1,5}$, Jeffrey M. Ashburner, MPH${ }^{2}$, Michael C. Jernigan, $\mathrm{MD}^{3}$, \\ Jaime Chang, $\mathrm{MD}^{3}$, Leila H. Borowsky, $\mathrm{MPH}^{2}$, Yuchiao Chang, PhD ${ }^{2,4}$, and Steven J. Atlas, MD \\ $\mathrm{MPH}^{2,4}$
}

\begin{abstract}
'Division of Research, Kaiser Permanente Northern California, Oakland, CA, USA; '2Division of General Medicine, Massachusetts General Hospital Boston, MA, USA; ${ }^{2}$ Laboratory of Computer Science, Massachusetts General Hospital, Boston, MA, USA; ${ }^{4}$ Harvard Medical School, Boston, MA, USA; ${ }^{5}$ Kaiser Permanente, Division of Research, Oakland, CA, USA.
\end{abstract}

\begin{abstract}
BACKGROUND: Lack of timely medication intensification and inadequate medication safety monitoring are two prevalent and potentially modifiable barriers to effective and safe chronic care. Innovative applications of health information technology tools may help support chronic disease management.

OBJECTIVE: To examine the clinical impact of a novel health IT tool designed to facilitate between-visit ordering and tracking of future laboratory testing.

DESIGN AND PARTICIPANTS: Clinical trial randomized at the provider level ( $n=44$ primary care physicians); patient-level outcomes among 3,655 primary care patients prescribed 5,454 oral medicines for hyperlipidemia, diabetes, and/or hypertension management over a 12month period.
\end{abstract}

MAIN MEASURES: Time from prescription to corresponding follow-up laboratory testing; proportion of follow-up time that patients achieved corresponding risk factor control (Alc, LDL); adverse event laboratory monitoring 4 weeks after medicine prescription.

KEY RESULTS: Patients whose physicians were allocated to the intervention $(n=1,143)$ had earlier LDL laboratory assessment compared to similar patients $(n=703)$ of control physicians [adjusted hazard ratio (aHR): 1.15 (1.011.32), $\mathrm{p}=0.04$ ]. Among patients with elevated LDL (486 intervention, 324 control), there was decreased time to LDL goal in the intervention group [aHR 1.26 (0.991.62)]. However, overall there were no significant differences between study arms in time spent at LDL or HbAlc goal. Follow-up safety monitoring (e.g., creatinine, potassium, or transaminases) was relatively infrequent (ranging from $7 \%$ to $29 \%$ at 4 weeks) and not statistically different between arms. Intervention physicians indicated that lack of reimbursement for non-visit-based care was a barrier to use of the tool.

CONCLUSIONS: A health IT tool to support between-visit laboratory monitoring improved the LDL testing interval but not LDL or HbAlc control, and it did not alter safety monitoring. Adoption of innovative tools to support

Electronic supplementary material The online version of this article (doi:10.1007/s11606-014-3152-y) contains supplementary material, which is available to authorized users.

Received September 5, 2014

Revised December 1, 2014

Accepted December 4, 2014

Published online January 6, 2015 physicians in non-visit-based chronic disease management may be limited by current visit-based financial and productivity incentives.

J Gen Intern Med 30(5):619-25

DOI: $10.1007 / \mathrm{s} 11606-014-3152-y$

(C) Society of General Internal Medicine 2014

$\mathrm{W}$ ith the aging of the population and ongoing obesity epidemic, the prevalence of common chronic conditions such as hyperlipidemia, type 2 diabetes, and hypertension, continues to increase $\left[{ }^{1},{ }^{2}\right]$. National quality data indicate that we are falling far short of optimal management of these conditions $\left[{ }^{3}\right]$. Because patients with these common chronic conditions are typically cared for in the primary care setting, primary care health system innovations designed to improve medication management have the potential to significantly improve the nation's health.

Lack of timely medication intensification has been identified as one potentially amenable barrier to effective chronic disease management $\left[{ }^{4-6}\right]$. Typically, medications are prescribed during an in-person clinic visit and a follow-up appointment is scheduled to evaluate the treatment result. In the ideal setting, laboratory evaluation of a new prescription result (e.g., subsequent LDL cholesterol after statin prescription or HbAlc after metformin) would precede the follow-up visit so that updated management decisions could be made. However, insufficient time during primary care visits, patient lack of follow-up with planned testing, and missed follow-up visits can all contribute to delayed initiation or modification of treatment $\left[{ }^{7-9}\right]$.

Medication prescriptions for chronic conditions are also a potentially important source of adverse drug events in the outpatient setting $\left[{ }^{10},{ }^{11}\right]$. One seminal study estimated that nearly one-quarter of outpatient prescriptions were associated with an adverse event, many of which were potentially preventable or ameliorable if recognized sooner $\left[{ }^{12}\right]$. Treatment guidelines for many commonly prescribed outpatient medicines often recommend laboratory safety monitoring (e.g., potassium levels, renal or liver function). However, there is 
wide variation in the current extent of post-prescription safety monitoring and in how this laboratory testing is coordinated with follow-up visits.

Given the need to monitor both the efficacy and safety of outpatient prescriptions, health IT tools to systematically support timely laboratory testing after medication prescription have the potential to improve the primary care of patients with common chronic conditions $\left[{ }^{13}\right]$. We hypothesized that between-visit laboratory monitoring and result surveillance could support more timely and safer medication intensification compared to usual care. We tested this hypothesis by designing, implementing, and evaluating a novel health IT tool ("Medication Metronome") in a randomized controlled trial. The goal of this intervention was to facilitate non-visit-based laboratory monitoring following the prescription of oral medications used to treat three common chronic conditions (hyperlipidemia, type 2 diabetes, and hypertension) managed in the primary care setting.

\section{RESEARCH DESIGN AND METHODS}

\section{Study Design and Randomization}

We conducted a cluster-randomized, controlled clinical trial in two primary care practices within the Massachusetts General Primary Care Practice-Based Research Network (MGPCPBRN) between 25 May 2012 and 24 May 2013 with outcome data collection until 24 November 2013. Because the intervention was directed towards primary care physicians (PCPs), we randomized the PCPs. The randomization was first stratified by practice. Within each practice, we created PCP pairs that had the smallest combined difference in panel size, years since graduation, and gender. We then used a random number generator to assign one to the intervention group and the other to the control group within each pair. By definition, PCPs could not be blinded to randomization status; however, assembly of data elements for analysis was masked to randomization status. By definition, PCPs could not be blinded to randomization status; however, assembly of data elements for analysis was masked to randomization status.

\section{Setting and Participants}

Practices within the MGPC-PBRN shared a uniform management and physician fee-for-service payment structure. The two practices participating in the study included 52 PCPs practicing either full or part time. Initial planning and user testing of the intervention tool was conducted with representatives from these two practices. The study was described at practice team meetings, and PCPs were invited either in person or by e-mail to participate. Of the 52 PCPs invited, 44 agreed to participate ( $85 \%$ ).

\section{Intervention Details}

With input from PCP advisors within the MGH-PBRN, we developed a novel health IT tool that was integrated into the electronic health record (EHR) used by the two practices. A new feature was added to the existing medication ordering screen that allowed study PCPs to order a follow-up laboratory test when initially prescribing a study-specific medication or when changing the dose (Figure 1). We limited this functionality to oral medications used to treat LDL-cholesterol levels (statins), type 2 diabetes (oral hypoglycemic agents), and hypertension [ACE-inhibitors, angiotensin receptor blockers (ARBs), and thiazide diuretics; see Supplemental Appendix 1 for list of the 108 eligible study medications and corresponding laboratory tests]. When one of these study medications was prescribed, the intervention physician had the opportunity to order a corresponding future laboratory test to evaluate the efficacy (e.g., HbAlc after metformin, LDL for a statin) or safety (e.g., serum potassium after a thiazide diuretic, renal function for an ACE-inhibitor) of the prescribed drug. Based on advice from our physician advisory panel, efficacy laboratory tests were defaulted to order, while safety laboratory tests required the PCP to actively initiate the order. A default time was set for when the future efficacy and safety tests should be completed (e.g., within 3 months for $\mathrm{HbAlc}$ ), but the PCP could also customize the follow-up time interval.

To support this new future laboratory test ordering feature, an underlying informatics surveillance and reminder system was developed. Named the "Medication Metronome", this system tracked the future laboratory tests ordered by an intervention physician prescribing a study medicine. The week before a scheduled laboratory test became due, the system automatically mailed the patient an explanatory letter signed by the ordering physician that included a laboratory test requisition form. If there was no result noted 2 weeks after the first letter was mailed, a second reminder letter and laboratory requisition was automatically mailed to the patient. If after an additional 2 weeks the requested test result was still not registered, a "missing" result was posted to the PCP's "Result List" page. Thus, this system was designed to support between-visit laboratory ordering and monitoring by both reaching out to patients when a scheduled test became due and alerting PCPs when a future scheduled test was not completed.

\section{Causal Model and Study Outcomes}

The Medication Metronome system was designed to improve the continuity of chronic disease management by supporting non-visit-based laboratory monitoring after prescription of commonly used medications to manage LDL-cholesterol, $\mathrm{HbAlc}$, and blood pressure levels. We hypothesized that this system would result in more timely follow-up laboratory testing compared to usual care. Because medication dose adjustments or prescription of additional agents for LDL and $\mathrm{HbA1c}$ control is typically driven by preceding test results, we further hypothesized that more timely test results would in turn lead to fewer delays in medication titration and ultimately better risk factor control. 


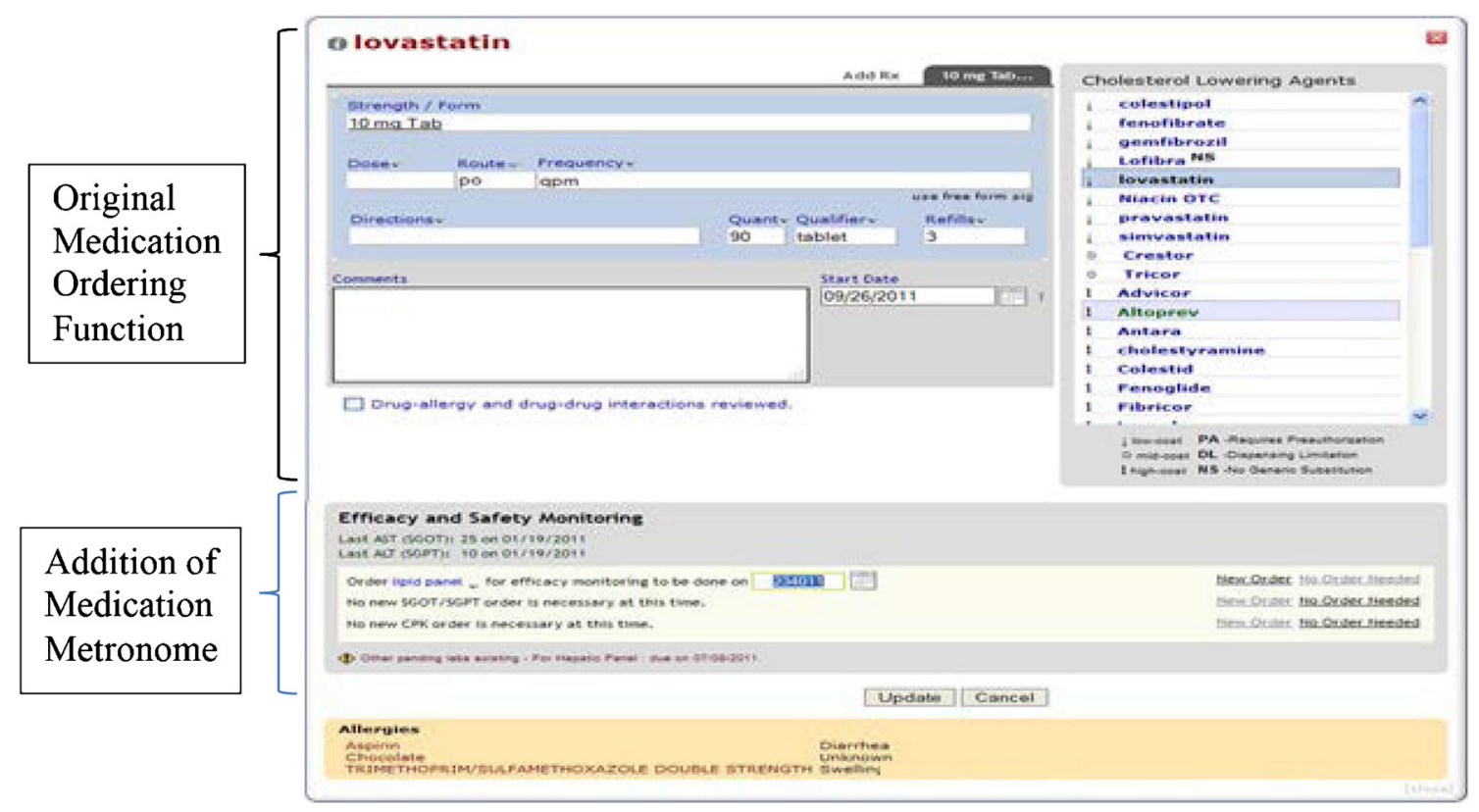

Figure 1 The medication prescribing interface used by all study physicians, with the addition of the "Medication Metronome" future laboratory ordering function for intervention physicians indicated by the bracket

Based on this causal model, we evaluated the following study outcomes and compared results between patients in intervention vs. control arms: (1) time from prescription of LDL- or HbA1c-related medicine to subsequent LDL or HbAlc test results, (2) time from medication prescription to the corresponding LDL or HbAlc control (defined as LDL $<$ $130 \mathrm{mg} / \mathrm{dl}$, or $100 \mathrm{mg} / \mathrm{dl}$ for patients with cardiovascular disease or diabetes; and $\mathrm{HbA} 1 \mathrm{c} \leq 7.0 \%$ ), and (3) proportion of time after medication prescription that the patient was at or below LDL or HbA1c goal. In addition to the efficacy of chronic disease management, we also evaluated whether the Medication Metronome system would increase safety-related laboratory monitoring. For this question, we compared the proportion of patients who had a corresponding test result 4 weeks after prescription (e.g., potassium after prescription of a thiazide diuretic; see Appendix for study drugs and corresponding laboratory tests). In a sensitivity analysis, we also compared safety test result proportions between study arms after 12 weeks.

Patient characteristics and laboratory data were obtained from a central electronic data repository at Partners Healthcare $\left[{ }^{14}\right]$. Prescribed study medications by participating PCPs were obtained from the EHR. Dates of laboratory tests and results were obtained over a 2-year period beginning 6 months before the 12-month study start date through 6 months after the study completion date. Physician characteristics were obtained from the hospital registrar.

We also surveyed study physicians after implementation of the Medication Metronome. Participants completed brief online or paper surveys that asked about time spent managing laboratory testing results and follow-up. Among intervention
PCPs at follow-up, we also specifically asked about facilitators and barriers to use of the tool.

\section{Statistical Methods}

For both study arms, patients were the unit of analysis. A patient became part of the analytic cohort when a participating physician prescribed one of the prespecified study medications used to treat hyperlipidemia, diabetes, or hypertension. Analyses were conducted for efficacy (separately for LDL and $\mathrm{HbAlc}$ ) and for safety monitoring (renal function for metformin; potassium for thiazides; liver function for statins; renal/ potassium for $\mathrm{ACE} / \mathrm{ARBs})$. Patients prescribed more than one class of medication could be in more than one analytic cohort. For patients prescribed the same medicine more than once during the study period, each prescribed medication was treated as a separate occurrence clustered within patients.

We compared patient characteristics between intervention and control groups using two-sample t-tests or chi-square tests, as appropriate. Comparisons between study arms were at the patient level and controlled for small but statistically significant patient baseline differences (age, gender, race, language, insurance, and baseline laboratory values) while accounting for clustering by PCP in multivariable models. We used Cox proportional hazards models with robust sandwich covariance matrix estimates (PROC PHREG, SAS version 9.3, SAS Institute, Cary, NC) for time-to-event analyses to account for clustering. We used linear regression for proportion of time spent at or below goal analyses, and logistic regression (PROC GENMOD) for our safety monitoring outcomes with general estimating equation techniques to account for clustering. All primary analyses were "intention to treat." In exploratory 
analyses, we also examined characteristics among eligible intervention patients comparing those who did vs. did not receive the Medication Metronome intervention. This study was approved by the Partners HealthCare institutional review board.

\section{RESULTS}

\section{Participants}

The 44 primary care physicians participating in the study had a mean of 17.8 years (SD: 11.4) of clinical practice experience and $27(61 \%)$ were female. There were no statistically significant PCP differences between study arms. Over the 12-month study period, 3,022 eligible study medications were prescribed for 2,049 patients in the intervention arm, and 2,432 eligible study medications were prescribed for 1,606 patients in the control arm. Study patients had a mean age of 65.8 years (SD: 13.0). There were a few small, though statistically significant, differences between study arm patients (Table 1), which were adjusted for in our multivariate models.

\section{Time to LDL Testing and Control}

There were 1,143 statins prescribed for 953 patients in the intervention arm and 703 statins prescribed for 621 patients in the control arm. After adjusting for baseline differences between groups, patients in the intervention arm had a shorter time interval to next LDL test after statin prescription [adjusted HR $1.15(1.01-1.32, \mathrm{p}=0.04)]$. As shown in Figure 2a, this

Table 1 Baseline patient characteristics, by intervention and control group $(3,655$ unique patients prescribed 5,454 study-eligible medications)

\begin{tabular}{|c|c|c|c|}
\hline & $\begin{array}{l}\text { Intervention } \\
\text { patients } \\
(n=2,049)\end{array}$ & $\begin{array}{l}\text { Control } \\
\text { patients } \\
(n=1,606)\end{array}$ & $\begin{array}{l}\text { P- } \\
\text { Value }\end{array}$ \\
\hline Age, mean (SD) & $65.9(13.1)$ & $65.7(12.8)$ & 0.64 \\
\hline Gender, female & $979(47.8 \%)$ & $850(52.9 \%)$ & 0.002 \\
\hline Ethnicity & & & 0.01 \\
\hline African-American & $148(7.2 \%)$ & $160(10.0 \%)$ & \\
\hline Asian & $91(4.7 \%)$ & $75(4.7 \%)$ & \\
\hline Hispanic & $63(3.1 \%)$ & $66(4.1 \%)$ & \\
\hline Other/unknown & $20(1.0 \%)$ & $14(0.9 \%)$ & \\
\hline Non-Hispanic white & $\begin{array}{l}1,712 \\
(84.3 \%)\end{array}$ & $1,291(80.4 \%)$ & \\
\hline Insurance status & & & 0.69 \\
\hline Commercial & $1,012(49.4 \%)$ & $791(49.3 \%)$ & \\
\hline Medicaid & $133(6.5 \%)$ & $120(7.5 \%)$ & \\
\hline Medicare & $854(41.7 \%)$ & $659(41.0 \%)$ & \\
\hline $\begin{array}{r}\text { No insurance, } \\
\text { self-pay/free }\end{array}$ & $49(2.4 \%)$ & $34(2.1 \%)$ & \\
\hline $\begin{array}{l}\text { Primary language } \\
\text { spoken, English }\end{array}$ & $1,952(95.3 \%)$ & $1,484(92.4 \%)$ & $<0.001$ \\
\hline $\begin{array}{l}\text { Clinic visits over } \\
3 \text { years, mean (SD) }\end{array}$ & $9.2(5.8)$ & $9.2(5.9)$ & 0.90 \\
\hline $\begin{array}{l}\text { Baseline HbA1c } \\
\text { value, mean (SD) }\end{array}$ & $\begin{array}{l}7.9(1.6) \\
\mathrm{N}=439\end{array}$ & $\begin{array}{l}8.1(1.9) \\
\mathrm{N}=424\end{array}$ & 0.05 \\
\hline $\begin{array}{l}\text { Baseline LDL } \\
\text { value, mean (SD) }\end{array}$ & $\begin{array}{l}117.7(39.8) \\
\mathrm{N}=1069\end{array}$ & $\begin{array}{l}121.6(43.8) \\
N=633\end{array}$ & 0.07 \\
\hline Diabetes & $607(29.6 \%)$ & $519(32.3 \%)$ & 0.08 \\
\hline Hypertension & $1,569(76.6 \%)$ & $1,231(76.7 \%)$ & 0.96 \\
\hline $\begin{array}{l}\text { Coronary artery } \\
\text { disease }\end{array}$ & $379(18.5 \%)$ & $290(18.1 \%)$ & 0.73 \\
\hline
\end{tabular}

corresponded to a 30-day improvement in the time it took for $40 \%$ of the patient cohort to have LDL testing after statin prescription. Among the subset of patients above LDL goal at baseline $(\mathrm{n}=810)$, intervention patients may have had a shorter time interval to reaching LDL goal [aHR 1.26 (0.99-1.62), Fig. 2b], although this result did not meet statistical significance $(\mathrm{p}=0.07)$. For the overall study period, the difference in time spent at goal after prescription was not significantly different between arms $(57.9 \%$ of time for intervention patients vs. $54.8 \%$ for control patients, adjusted $p$-value $=0.30$ ).

\section{Time to HbA lc Testing and Control}

There were fewer patients prescribed oral medications for diabetes control than LDL control during the 12-month study period (450 prescriptions for 318 intervention patients, 430 prescriptions for 300 control patients). As shown in Figure 2c and $\mathrm{d}$, differences in test result timing and $\mathrm{HbAlc}$ control were small and not statistically significant. The time spent at $\mathrm{HbAlc}$ goal $\leq 7.0 \%$ (or $\leq 9.0 \%$ ) for the overall study period was also similar between arms $(32.5 \%$ vs. $34.3 \%$ of time $\leq 7.0 \%$, p $=$ $0.6 ; 83.0 \%$ vs. $81.6 \%$ of time $\leq 9.0 \%, p=0.55$ ).

\section{Medication Safety Monitoring}

Rates of follow-up laboratory monitoring within 4 weeks of prescription were highest for renal function testing after prescription of an ACE/ARB (25.5\%) and lowest for liver function testing after statin prescription (7.4\%, Table 2). There were no differences between study arms based on an intentionto-treat analysis, reflecting the low rate of Medication Metronome use for this purpose by intervention physicians. In a sensitivity analysis, this lack of intervention effect remained evident at 12 weeks (data not shown).

\section{Eligible Intervention Patients Who Did Vs. Did Not Receive Intervention}

Among the 2,049 patients with eligible prescriptions in the intervention arm, only 442 (21.6\%) had a future reminder letter scheduled through the Medication Metronome system. In this group of potentially eligible intervention patients, those who actually received the intervention were substantially more likely to have an established relationship $\left[{ }^{15}\right]$ with their PCP (96.8\% vs. $80.2 \%$ for intervention patients who did not receive a Medication Metronome follow-up order, $\mathrm{p}<0.001$ ). These "On-Treatment" patients also had fewer annual visits $(8.3 \pm 5.0$ visits over 3 years vs. $9.5 \pm 5.9, p<0.001)$ and higher baseline LDL levels $(122.7 \pm 43.0$ vs. $114.3 \pm 37.0, \mathrm{p}=0.001)$.

\section{Provider Surveys}

Postintervention surveys were completed by $91 \%$ (20 of 22) of intervention PCPs. Among respondents, $30 \%$ indicated that Medication Metronome improved their ability to provide timely medication management, while the remaining $70 \%$ reported no change. Most intervention group PCPs (80 \%) reported 

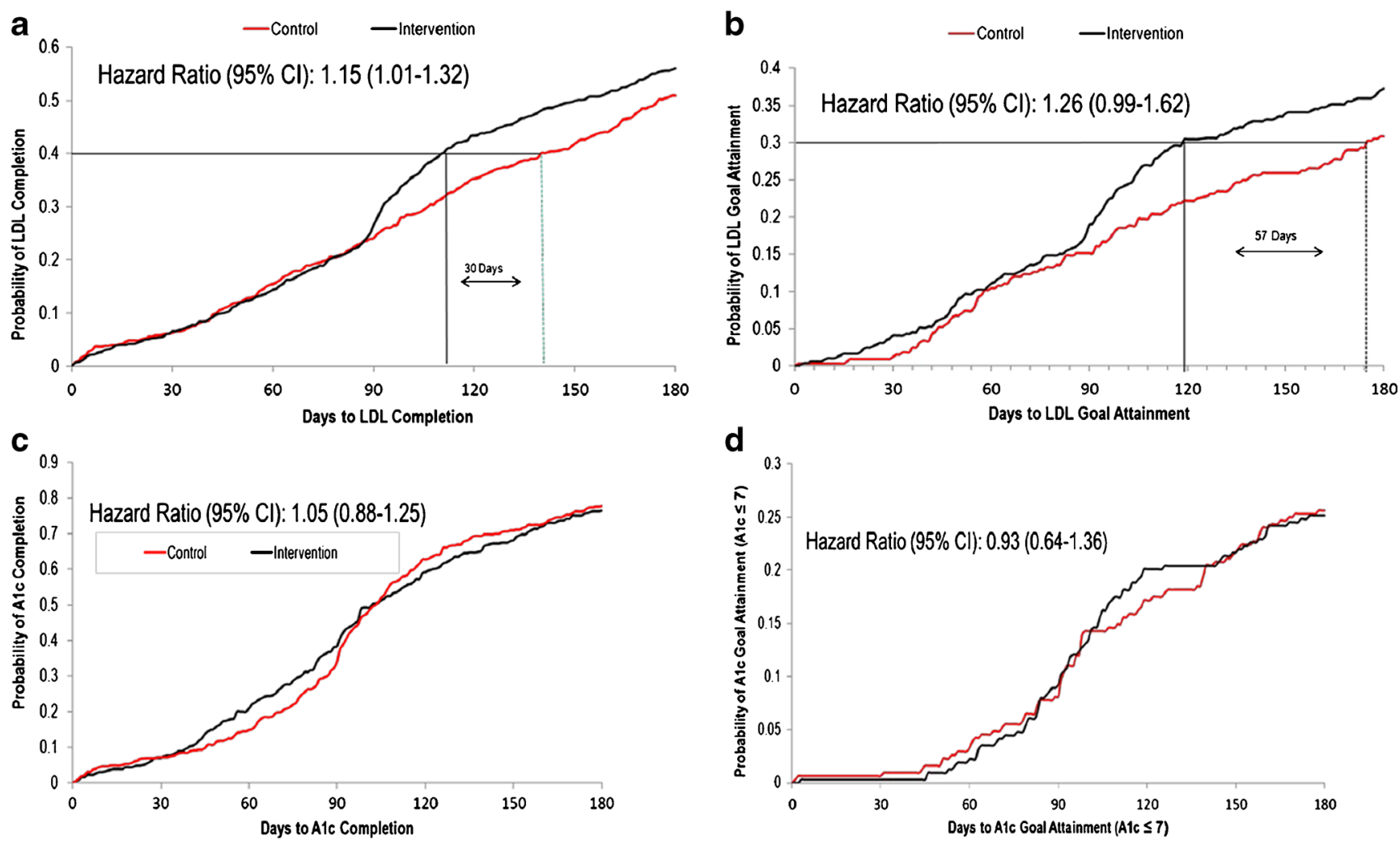

Figure 2 Time from prescription to next laboratory testing (a, c) and to achieving the risk factor goal (b, d) among patients with elevated LDL $(>100 \mathrm{mg} / \mathrm{dl})$ or elevated HbA1c $(>7.0 \%)$ at the time of prescription

barriers to using the Medication Metronome tool including poor alignment with current visit-based reimbursement practices.

Table 2 Percentage of laboratory test results obtained within 4 weeks after medication prescription

\begin{tabular}{|c|c|c|c|c|}
\hline & Intervention & Control & Difference & \\
\hline $\begin{array}{l}\text { Laboratory } \\
\text { result } \\
\text { (prescription) }\end{array}$ & $\%(\mathrm{~N} /$ total $)$ & $\begin{array}{l}\% \\
(\mathrm{~N} / \text { total })\end{array}$ & $\begin{array}{l}\mathrm{I} \%-\mathrm{C} \% \\
(95 \% \mathrm{CI})\end{array}$ & $\begin{array}{l}\mathrm{P}- \\
\text { value* }\end{array}$ \\
\hline $\begin{array}{l}\text { AST/ALT } \\
\text { (statin) }\end{array}$ & $\begin{array}{l}6.7 \% \\
(76 / 1,134)\end{array}$ & $\begin{array}{l}8.6 \% \\
(60 / 699)\end{array}$ & $\begin{array}{l}-2.0 \% \\
(-3.9-6.0 \\
\%)\end{array}$ & 0.16 \\
\hline $\begin{array}{l}\text { Creatinine } \\
\text { (metformin) }\end{array}$ & $\begin{array}{l}13.7 \% \\
(61 / 445)\end{array}$ & $\begin{array}{l}16.2 \% \\
(69 / 425)\end{array}$ & $\begin{array}{l}-2.9 \% \\
(-7.1-2.7 \\
\%)\end{array}$ & 0.29 \\
\hline $\begin{array}{l}\text { Creatinine } \\
\text { (ACE/ARB, } \\
\text { thiazide) }\end{array}$ & $\begin{array}{l}26.9 \% \\
(380 / 1,411)\end{array}$ & $\begin{array}{l}24.0 \% \\
(311 / \\
1,2960)\end{array}$ & $\begin{array}{l}2.9 \% \\
(-2.4-9.0 \\
\%)\end{array}$ & 0.30 \\
\hline
\end{tabular}

$N=$ Number of laboratory test results within 4 weeks/number of medications prescribed

Difference, $I \%$ - C\% $(95 \% C I)=$ difference between the intervention and control arms in \% patients with laboratory tests within 4 weeks of medication prescription after adjusting for baseline imbalances $(95 \%$ confidence interval)

*p-values are adjusted for patient baseline differences between study arms

$A L T / A S T=$ aspartate transaminase/alanine transaminase

$A C E / A R B=$ angiotensin converting enzyme inhibitor/angiotensin receptor blocker

\section{DISCUSSION}

We conducted a cluster-randomized clinical trial to evaluate the impact of an innovative health IT tool designed to improve the medical management of three common chronic diseases (hyperlipidemia, type 2 diabetes, and hypertension). For primary care patients with these conditions, we hypothesized that improved, non-visit-based laboratory monitoring would lead to more timely medication titration and therefore better disease control. We developed and implemented a simple modification to the EHR medication prescribing function that enabled PCPs to schedule future laboratory tests when prescribing a study medication. The completion of these future laboratory orders was tracked by an underlying informatics platform designed for surveillance, automated patient outreach, and the capacity to inform PCPs of missing tests.

We found that compared to the patients of physicians in the control arm, patients whose physicians had access to the intervention had a significantly shorter time interval between statin prescription and subsequent LDL testing results. Although not quite reaching statistical significance, this shortened prescription/testing cycle appeared to also decrease the time to achieving LDL control in the subset of patients with elevated levels at baseline. However, similar results were not seen for 
HbA1c control among oral medications used to manage type 2 diabetes, and the percentage of time a patient was at or below the risk factor goal did not differ among treatment groups. Overall, the Medication Metronome was used in less than one-quarter of potentially eligible intervention patients. Thus, while the goal of improving the efficacy of medication prescribing showed promise, the overall intervention impact may have been hampered by underuse of the tool among intervention providers.

Prior interventions using health IT tools to improve medication intensification have also had higher success for cholesterol management compared to glycemic management $\left[{ }^{16},{ }^{17}\right]$. This result may reflect differences between the two conditions: there is a strong direct link between statin prescription and LDL lowering, whereas HbAlc control is a complex, patientspecific interplay among medications, lifestyle changes, and the underlying disease phenotype. Alternatively, the smaller number of prescriptions for diabetic medications may have given us insufficient power to show an $\mathrm{HbAlc}$ difference in our intention-to-treat analysis.

We also examined the impact of the IT tool in supporting safety-related laboratory monitoring after medication prescribing. Prior research has found that many PCPs are dissatisfied with how outpatient laboratory results are managed, with $83 \%$ reporting delays in reviewing results over the preceding 2 months $\left[{ }^{18}\right]$. In a survey of 161 primary care providers, for example, Boohaker et al. found major systemic problems: Approximately $24 \%$ of physicians had no reliable method to make sure that the results of all tests ordered were received, $33 \%$ did not always notify patients of abnormal results (often because the patient was expected to have a follow-up clinic visit), and only $23 \%$ of physicians reported having a reliable method for identifying patients overdue for follow-up $\left[{ }^{19}\right]$. Despite these reported concerns, in our study we found low rates of "safety" laboratory monitoring after prescription of statins, ACE/ARBs, and metformin among intervention and control group PCPs. One explanation for these results is the relative lack of outcomes evidence to support many of the suggested drug-monitoring tests. Indeed, based on feedback from our physician stakeholder group, ordering of safety follow-up laboratory tests was not set as a default option but rather required an additional step to order, reflecting the clinical impression that these tests were frequently not necessary. Reasons given by our stakeholder advisory board for not making this safety testing the default option included the fact that many patients have had prior monitoring that did not require repeating.

There are several limitations to our study that bear further discussion. While our physician stakeholders and primary care physicians appeared enthusiastic about the Medication Metronome during the development and initial implementation phases of the study, in practice the tool was not widely used by intervention PCPs. Study participants did not embrace this method of non-visit-based care, with only 660 medication prescriptions using the Medication Metronome ordering option ( $21 \%$ of possible orders). Our survey and exit interviews identified several factors that might have contributed to this underuse. Barriers included: (1) the misalignment of visitbased reimbursement and productivity requirements with a non-visit-based model of care, (2) the desire by both patients and PCPs to rely on personal clinical encounters for medication management discussions, and (3) the frustrations some physicians felt at the many concurrent changes and initiatives that were implemented during the study period that focused on optimizing clinical productivity.

Another barrier raised by intervention PCPs after study completion was the need for creating an optimal workflow strategy. Unlike scheduling a follow-up clinic visit, nonvisit-based clinical work often does not have a clearly established or standardized workflow. As might be expected from experienced clinicians working in a busy practice environment, many study PCPs had already developed their own strategies to coordinate laboratory follow-up and monitoring such as relying on nurses or using personal e-mails. Given the limited time available for clinical management outside of the visit setting, many physicians may have found it easier to schedule a follow-up visit, even though any future missed appointments would delay medication titration. Another potential impediment for use of the tool may have been the need to take time during the visit to explain the process of a non-visit-based follow-up for patients who were not accustomed to this care model. Finally, many intervention physicians noted that a substantial minority of tests were completed at laboratory facilities outside of the MGPC-PBRN. These results were not captured by the Medication Metronome system, leading to erroneous "missing test" reminder letters that the PCPs needed to explain to the patients who received them.

The US health system is undergoing much needed change. The ongoing implementation of the Affordable Care Act (ACA) includes incentives to reorganize health care delivery systems as accountable care organizations that take a population-level view of care quality. Modernizing the current health care system may require fundamental changes to how medicine is currently practiced. Part of this change includes an incentive structure to increase the meaningful use of health IT in clinical care $\left[{ }^{20}\right]$. Health policy and reimbursement changes that support non-visit-based care models as a way to deliver high-quality, efficient care are needed to encourage greater adoption of innovative tools designed to support visit-independent medication management. Specifically, new payment models and workflow practices that integrate non-visit clinical work may be needed before visitindependent medication management systems will be more widely adopted $\left[{ }^{21}\right]$. As the organization of primary care systems evolve, we anticipate that tools such as the Medication Metronome that support clinical care outside of the traditional in-person visit may have greater adoption and clinical impact. 
Conflict of Interest: The authors report no conflicts of interest.

Corresponding Author: Richard W. Grant, MD MPH; Kaiser Permanente, Division of Research, 2000 Broadway, Oakland, CA 94612, USA (e-mail: Richard.W.Grant@KP.org).

\section{REFERENCES}

1. Go AS, Mozaffarian D, Roger VL, et al. Executive summary: heart disease and stroke statistics-2013 update: a report from the American Heart Association. Circulation. 2013;127(1):143-152.

2. The State of US Health, 1990-2010. Burden of diseases, injuries, and risk factors. JAMA. 2013;310(6):591-608.

3. Ali MK, Bullard KM, Saaddine JB, Cowie CC, Imperatore G, Gregg EW. Achievement of Goals in US Diabetes Care, 1999-2010. New Engl J Med. 2013;368(17):1613-1624.

4. Rodondi N, Peng T, Karter AJ, et al. Therapy modifications in response to poorly controlled hypertension, dyslipidemia, and diabetes mellitus. Ann Intern Med. 2006;144(7):475-484.

5. Ho PM, Magid DJ, Shetterly SM, et al. Importance of therapy intensification and medication nonadherence for blood pressure control in patients with coronary disease. Arch Intern Med. 2008;168(3):271-276.

6. Grant RW, Buse JB, Meigs JB. Quality of diabetes care in US academic medical centers: low rates of medical regimen change. Diabetes Care. 2005;28(2):337-442.

7. Ostbye T, Yarnall KS, Krause KM, Pollak KI, Gradison M, Michener JL. Is there time for management of patients with chronic diseases in primary care? Ann Fam Med. 2005;3(3):209-214.

8. Karter AJ, Parker MM, Moffet HH, et al. Missed appointments and poor glycemic control: an opportunity to identify high-risk diabetic patients. Med Care. 2004;42(2):110-115.

9. Morrison I. The future of physician's time. Anna Intern Med. 2000; 132(1):80-84.
10. Gandhi TK, Seger AC, Overhage JM, et al. Outpatient adverse drug events identified by screening electronic health records. J Patient Saf. 2010;6(2):91-96.

11. Gurwitz JH, Field TS, Harrold LR, et al. Incidence and preventability of adverse drug events among older persons in the ambulatory setting. JAMA. 2003;289(9):1107-1116.

12. Gandhi TK, Weingart SN, Borus $\mathbf{J}$, et al. Adverse drug events in ambulatory care. New Engl J Med. 2003;348(16):1556-1564.

13. Grant RW, Middleton B. Improving primary care for patients with complex chronic diseases: can health information technology play a role? CMAJ. 2009; 181(1-2):17-18.

14. Murphy SN, Chueh HC. A security architecture for query tools used to access large biomedical databases. Proc AMIA Symp. 2002:552556

15. Atlas SJ, Chang Y, Lasko TA, Chueh HC, Grant RW, Barry MJ. Is this "my" patient? Development and validation of a predictive model to link patients to primary care providers. J Gen Intern Med. 2006;21(9):973-978.

16. Lester WT, Grant RW, Barnett GO, Chueh HC. Randomized controlled trial of an informatics-based intervention to increase statin prescription for secondary prevention of coronary disease. J Gen Intern Med. 2006;21(1):22-29.

17. Selby JV, Schmittdiel JA, Fireman B, et al. Improving treatment intensification to reduce cardiovascular disease risk: a cluster randomized trial. BMC Health Serv Res. 2012;12(1): 183.

18. Poon EG, Gandhi TK, Sequist TD, Murff HJ, Karson AS, Bates DW. "I wish I had seen this test result earlier!": Dissatisfaction with test result management systems in primary care. Arch Intern Med. 2004; 164(20):2223-2228.

19. Boohaker EA, Ward RE, Uman JE, McCarthy BD. Patient notification and follow-up of abnormal test results. A physician survey. Arch Intern Med. 1996; 156(3):327-331.

20. Jha AK. Meaningful use of electronic health records: the road ahead. JAMA. 2010;304(15):1709-1710.

21. Siddiqui M, Berkowitz SA. Shared savings models for ACOs incentivizing primary care physicians. J Gen Intern Med. 2014;29(6):832-834. 